\title{
Maternal and fetal outcome of malaria in pregnancy
}

\author{
Gowthami Palem ${ }^{1 *}$, Sharan J. Pal ${ }^{2}$
}

\begin{abstract}
${ }^{1}$ Department of Obstetrics and Gynecology, Medical College, Mahbubnagar, Telangana, India
${ }^{2}$ Department of Obstetrics and Gynecology, Kasturba Medical College, Kasturba Medical College, Mangalore, Karnataka, India
\end{abstract}

Received: 02 August 2019

Accepted: 09 September 2019

\author{
*Correspondence: \\ Dr. Gowthami Palem, \\ E-mail: gowthami.palem@gmail.com
}

Copyright: () the author(s), publisher and licensee Medip Academy. This is an open-access article distributed under the terms of the Creative Commons Attribution Non-Commercial License, which permits unrestricted non-commercial use, distribution, and reproduction in any medium, provided the original work is properly cited.

\begin{abstract}
Background: Malaria, an oldest recorded parasitic infection transmitted by mosquitoes, is one of the most devastating infectious diseases. Mangalore, government headquarters of Dakshin Kannada district in Karnataka, receives high rainfall and exhibits humid tropical environment, harboring high vector density and contributing to high incidences of malaria. The aim of the present study was to observe maternal and fetal outcome of malaria in pregnancy.

Methods: This is an observational prospective study conducted from September 2014 to September 2015 at Lady Goschen Hospital, Mangalore which serves as tertiary level hospital. Study population included were pregnant women diagnosed to have malaria by rapid diagnostic test or microscopy as an outpatient or inpatient during the study period. Complications were noted in terms of maternal and foetal complications.

Results: A total of 12600 pregnant women attended LGH during study period out of which 41 were positive for malaria which has a prevalence of $0.32 \%$. Among the malaria cases, 23 cases were primigravidae and 18 were multigravidae. The commonest pathogen found was Plasmodium vivax accounting for $63.4 \%$. Regarding complications maternal anaemia and thrombocytopenia accounted for $34.1 \%$ and $26.8 \%$ respectively. Pregnancy outcomes were $17 \%$ of spontaneous miscarriage, $21.8 \%$ preterm deliveries, $29.1 \%$ low birth weight babies and $2.4 \%$ perinatal deaths. Conclusions: Malaria adversely affects both pregnant female as well as fetus. It is therefore advised all patients with fever in pregnancy must have screening for malarial parasite and treated adequately by medicine and supportive care to improve the maternal and fetal outcome.
\end{abstract}

Keywords: Fever, Malaria, Plasmodium, Pregnancy

\section{INTRODUCTION}

Malaria, an oldest recorded parasitic infection transmitted by mosquitoes, is one of the most devastating infectious diseases. In 2017, 219 million people were affected and accounted for 435000 deaths worldwide. ${ }^{1}$ Sub-Saharan Africa has the highest disease burden accounting for $89 \%$ of malaria cases in the world. ${ }^{2,3}$ According to NVBDCP (National Vector Borne Disease Control Programme), India accounts for 0.7 to 1.6 million cases and 400 to
1000 deaths annually. Malaria is highly endemic and persistent throughout the year in several parts of South Western regions of India, including a substantial portion of Karnataka state. Mangalore is the government headquarters of Dakshin Kannada district in Karnataka, which receives high rainfall and exhibits humid tropical environment, harboring high vector density and contributing to high incidences of malaria. In the last two decades, rapid industrialization resulted in a substantial number of immigrant labourers from other parts of India, 
prominently from Northeastern regions where malaria is highly endemic. This resulted in the spread and high incidences of malaria in Mangalore city and surrounding areas. In 2014, Mangalore contributes to $59 \%$ of malaria cases in Karnataka. ${ }^{4}$

Increased risk of malaria is seen in pregnant women, children and immuno-compromised patients. ${ }^{5}$ Pregnant women especially primigravida are more susceptible in second half of pregnancy. ${ }^{6}$ Atypical, severe and more fatal in pregnancy. ${ }^{5}$ Maternal complications include anemia, thrombocytopenia, hypoglycemia, cerebral malaria etc.

Fetal complications like miscarriage, congenital infections, preterm delivery, low birth weight babies, perinatal death etc. ${ }^{7}$

LBW reflects intrauterine growth restriction and preterm delivery indicating infant morbidity which can result in infant mortality, poor cognition and non-communicable diseases later in life. LBW was defined as birth weight less than $2500 \mathrm{gm}$ and preterm birth as birth <37weeks gestation. The gestational age was established by the women's last menstrual period and adjusted by ultrasound during antenatal visit. ${ }^{8}$

\section{METHODS}

\section{Study population and methodology}

This is a retrospective study of pregnant women who visited Lady Goschen hospital, a tertiary care centre at Mangalore between September 2014 to august 2015 with fever. A detailed history and clinical examination was done to ascertain the cause of fever. Haemoglobin, total and differential leucocyte count, rapid diagnostic tests (RDTs) for malaria, routine urine examinations were done. Additional investigations such as urine culture, sputum for acid-fast bacilli (AFB) etc. were done on the merits of the case. Microscopy of blood smears was done for species identification for all malaria positive pregnant women. A total of 41 patients were found to be smear positive for plasmodium.

The patients were treated with tablet chloroquine, quinine or artemisinin combination treatment depending on species identification, trimester and severity of malaria. Maternal demographic details, maternal and fetal complications were noted during the study period. Maternal complications include anemia, thrombocytopenia, jaundice, shock etc., and fetal complications like miscarriage, low birth weight, Intrauterine death etc. Data was obtained from outpatient records, case sheets and labor records of the hospital, analyzed by calculation of percentages.

\section{Inclusion criteria}

Study population included were pregnant women diagnosed to have malaria by rapid diagnostic test or microscopy as an outpatient or inpatient during the study period. Microscopy of blood smears was done for species identification.

\section{Exclusion criteria}

Cases of chronic anaemia, ITP, Chronic diseases like renal disease, liver disorders, chronic hypertension etc. Maternal demographic details, maternal and fetal complications were analyzed during the study period.

\section{RESULTS}

A total of 12600 pregnant women attended LGH during study period out of which 41 were positive for malaria. Prevalence of malaria in pregnancy during the study period was $0.32 \%(\mathrm{n}=41)$. Out of 41 cases, $P$. vivax, falciparum and mixed malaria accounts for 26, 9 and 6 cases respectively showing the predominant pathogen as $P$. vivax (Figure 1).

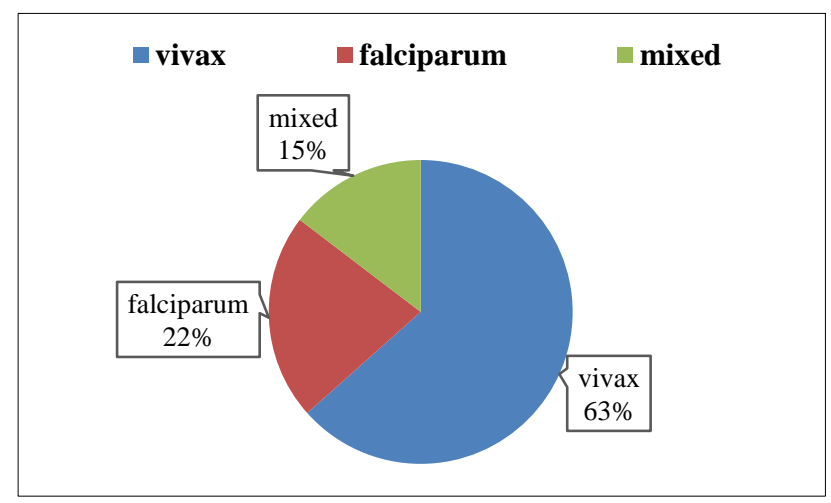

Figure 1: Types of parasitaemia causing malaria.

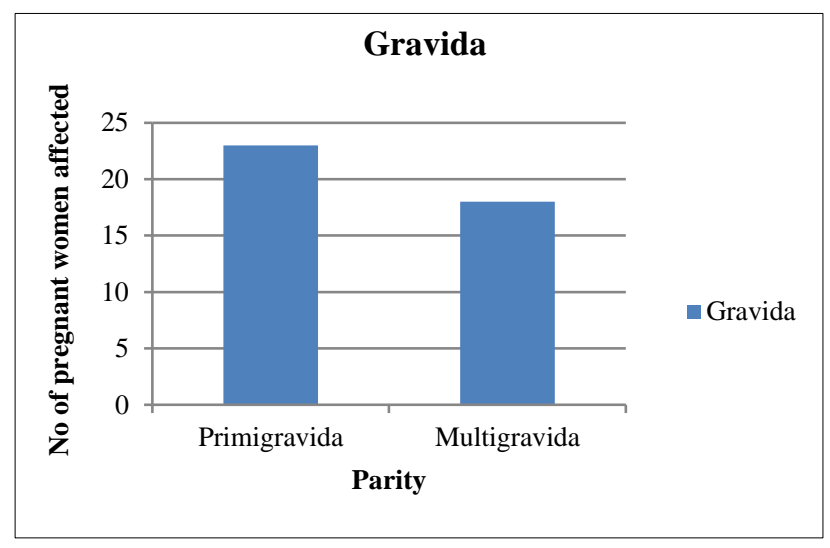

Figure 2: Malarial parasitaemia in relation to parity.

Among the malaria cases, 23 cases were primigravidae and 18 were multi-gravidae, accounting for $56 \%$ and $44 \%$ respectively (Figure 2).

Out of 41 cases, maternal anemia was present in 14 cases of which $8(19.5 \%)$ were primigravida and $6(14.6 \%)$ were multi-gravida (Table 1). 
Table 1: Prevalence of maternal anaemia in relation to parity.

\begin{tabular}{|lll|}
\hline $\begin{array}{l}\text { Maternal } \\
\text { anemia }\end{array}$ & $\begin{array}{c}\text { Primigravida } \\
\% \text { (no. of cases) }\end{array}$ & $\begin{array}{l}\text { Multigravida } \\
\% \text { (no. of cases) }\end{array}$ \\
\hline Present & $19.5 \%(8)$ & $14.6 \%(6)$ \\
\hline Absent & $36.5 \%(15)$ & $29.2 \%(12)$ \\
\hline
\end{tabular}

Table 2: Prevalence of maternal thrombocytopenia in relation to parity.

\begin{tabular}{|lll|}
\hline $\begin{array}{l}\text { Maternal } \\
\text { thrombocytopenia }\end{array}$ & $\begin{array}{l}\text { Primigravida } \\
\% \text { (no. of } \\
\text { cases) }\end{array}$ & $\begin{array}{l}\text { Multigravida } \\
\% \text { (no. of } \\
\text { cases) }\end{array}$ \\
\hline Present & $19.5 \%(8)$ & $7.3 \%(3)$ \\
\hline Absent & $36.5 \%(15)$ & $36.5 \%(15)$ \\
\hline
\end{tabular}

Maternal thrombocytopenia was seen in 11 cases of which $8(19.5 \%)$ were primigravida and $3(7.3 \%)$ were multigravida (Table 2).

Table 3: Prevalence of foetal complications among affected pregnant in relation to parity.

\begin{tabular}{|lcl|}
\hline $\begin{array}{l}\text { Type of fetal } \\
\text { complication }\end{array}$ & $\begin{array}{l}\text { Primigravida } \\
\% \text { (no. of } \\
\text { cases) }\end{array}$ & $\begin{array}{l}\text { Multigravida } \\
\% \text { (no. of } \\
\text { cases) }\end{array}$ \\
\hline $\begin{array}{l}\text { Spontaneous } \\
\text { miscarriage }\end{array}$ & $9.7 \%(4)$ & $7.3 \%(3)$ \\
\hline Preterm delivery & $9.7 \%(4)$ & $12.1 \%(5)$ \\
\hline Low birth weight & $17 \%(7)$ & $12.1 \%(5)$ \\
\hline Perinatal death & $2.4 \%(1)$ & $0 \%(0)$ \\
\hline
\end{tabular}

Obstetric outcomes includes, 7 cases (17\%) of spontaneous miscarriage, all belonging to first trimester, 9 cases $(21.8 \%)$ of preterm deliveries, $12(29.1 \%)$ cases of low birth weight babies and 1 case $(2.4 \%)$ of perinatal death (Table 3).

Table 4: Maternal complications caused by different malarial pathogens.

\begin{tabular}{|lcc|}
\hline $\begin{array}{l}\text { Type of maternal } \\
\text { complication }\end{array}$ & $\begin{array}{l}\text { P. vivax } \\
\%\end{array}$ & $\begin{array}{l}\text { P. falciparum } \\
\%\end{array}$ \\
\hline Maternal anemia & $86 \%$ & $14 \%$ \\
\hline $\begin{array}{l}\text { Maternal } \\
\text { thrombocytopenia }\end{array}$ & $37 \%$ & $63 \%$ \\
\hline
\end{tabular}

Complications caused by different pathogens accounted for maternal anemia were $86 \%$ and $14 \%$, maternal thrombocytopenia were $37 \%$ and $63 \%$ of $P$. vivax and falciparum respectively (Table 4 ).

Obstetric complications caused by $P$. vivax and falciparum accounted for $28 \%$ and $72 \%$ of spontaneous miscarriage, $66 \%$ and $34 \%$ of preterm deliveries, $71 \%$ and $29 \%$ of low birth weight babies, $0 \%$ and $100 \%$ of perinatal deaths respectively (Figure 3).

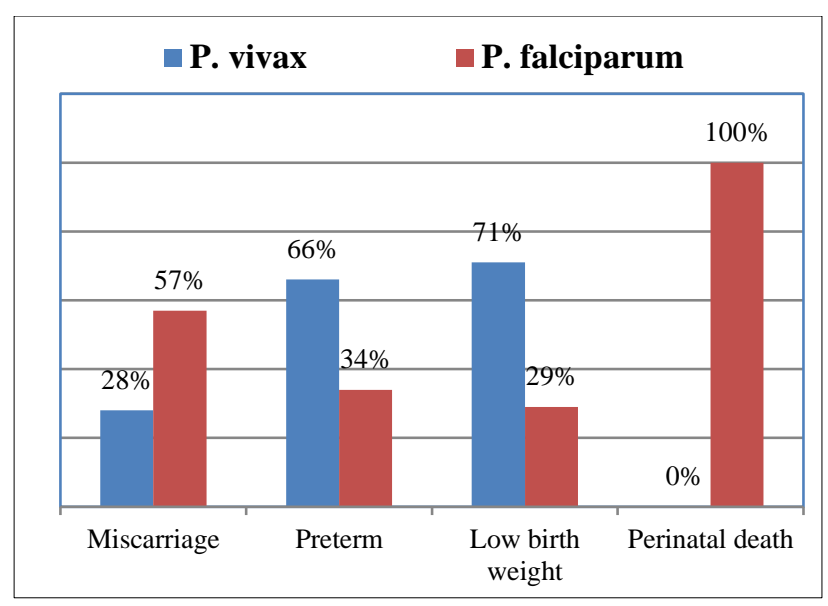

Figure 3: Foetal complications in relation to type of parasitaemia.

\section{DISCUSSION}

The number of malaria cases worldwide seems to be increasing due to increasing transmission risk in areas where malaria control has declined, the increasing prevalence of drug-resistant strains of parasites, and in a relatively few cases, massive increases in international travel and migration. ${ }^{9}$ The prevalence of malaria in pregnancy in the present study was $0.32 \%$ which comes under high transmission area.

Malaria is more often seen in primigravida than multigravida. ${ }^{10}$ Multigravida women in endemic areas are somewhat protected from placental malaria and this may be the result of maternal antibodies preventing cytoadhesion of the parasite to the placenta. ${ }^{11}$ Similar finding was noted in studies by Desai $\mathrm{M}$ et al. ${ }^{12}$

In laboratory, malaria is diagnosed using different techniques: Conventional microscopic diagnosis by staining thin and thick peripheral blood smears, RDTs, serological test, and molecular diagnostic methods, such as polymerase chain reaction. ${ }^{13}$ Some advantages and shortcomings of these methods have also been described, related to sensitivity, specificity, accuracy, precision, time consumed, cost-effectiveness, labor intensiveness, the need for skilled microscopists. Since the WHO recognized the urgent need for new, simple, quick, accurate, and cost-effective diagnostic tests for determining the presence of malaria parasites, to overcome the deficiencies of light microscopy, numerous new malaria-diagnostic techniques have been developed like RDTs. This, in turn, has led to an increase in the use of RDTs for malaria, which are fast and easy to perform, and do not require electricity or specific equipment. ${ }^{14}$ RDTs appear as highly valuable, rapid malaria-diagnostic tool for healthcare workers; however, it must currently be used in conjunction with other methods to confirm the results, characterize infection, and monitor treatment. Microscopic detection and identification of Plasmodium species in Giemsa-stained thick blood films (for 
screening the presenting malaria parasite) and thin blood films (for species confirmation) remain the gold standard for laboratory diagnosis. ${ }^{15}$

In the present study, $P$. vivax accounts for $63.4 \%$ of cases followed by $P$. falciparum of $21.9 \%$ but other studies haven't found similar associations. ${ }^{10}$

In a study by Shulman CE et al, the prevalence of anemia among pregnant women with malaria was $38 \%$ whereas in present study it was $34 \% .{ }^{16}$ The cause of anemia particularly in pregnant lady is because of hemolysis of parasitized blood and increased demand of blood during pregnancy. Anemia increases perinatal morbidity and mortality and increased risk of postpartum hemorrhage.

Thrombocytopenia in malaria probably occurs through peripheral destruction, sequestration or excessive removal of the platelets by the spleen, as well as platelet consumption by the process of disseminated intravascular coagulation. Platelets have been reported to enhance clumping of $P$. falciparum-infected erythrocytes, and this process might lead to pseudo thrombocytopenia. $26.8 \%$ cases show maternal thrombocytopenia in malaria cases where as it had ranged from $50-56 \%$ in other studies. ${ }^{17}$

Malaria in pregnancy is thought to affect birth outcomes through two mechanisms, intrauterine growth restriction (IUGR) and preterm delivery, the former has been consistently associated with placental infection while the latter appears to correlate with systemic manifestations of malaria infection in the mother. However, accurate determination of gestational age is required to distinguish IUGR from preterm delivery. ${ }^{18}$ In the present study, incidence of miscarriage, preterm delivery, IUGR and perinatal deaths accounted for $17 \%, 21.9 \%, 29.2 \%$ and $2.4 \%$ respectively. Of these $P$. vivax and falciparum contributed to $28 \%$ versus $57 \%$ of miscarriage cases, $66 \%$ versus $34 \%$ in preterm deliveries, $71 \%$ versus $29 \%$ of IUGR cases and $0 \%$ versus $100 \%$ of perinatal deaths.

\section{CONCLUSION}

Malaria adversely affects the both pregnant female as well as fetus. It increases the incidence of anemia, thrombocytopenia, renal failure, hepatic failure, multi organ dysfunction in pregnant female and also increases the risk of spontaneous abortion, intra-uterine growth retardation, premature delivery, IUGR and perinatal deaths. It is therefore advised all patients with fever in pregnancy must have screening for malarial parasite and treated adequately by medicine, close monitoring and supportive care to improve the maternal and fetal outcome.

\section{ACKNOWLEDGMENTS}

Authors would like to the women who participated in this study and to all the staff of Lady Goschen hospital for their support and guidance.
Funding: No funding sources Conflict of interest: None declared

Ethical approval: Not required

\section{REFERENCES}

1. Sitalakshmi S, Srikrishna A, Devi S. Changing trends in malaria: A decade's experience at a referral hospital. Indian J Pathol Microbiol. 2003;46:399-401.

2. Newman RD, Hailemariam A, Jimma D, Degifie A, Kebode D, Rietveld AE, et al. Burden of malaria during pregnancy in areas of stable and unstable transmission in Ethiopia during a nonepidemic year. Journal Infect Dis. 2003;188:1259-61.

3. Tusting LS, Thwing J, Sinclair D, Fillinger U, Gimnig J, Bonner KE, et al. Mosquito larval source management for controlling malaria. Cochrane Database Syst Rev, 2013. Available at: https://doi.org/10.1002/14651858.CD008923.pub2.

4. Desai M, Ter Kuile FO, Nosten F, McGready R, Asamoa K. Epidemiology and burden of malaria in pregnancy. Lancet Infect Dis. 2007;7(2):93-104.

5. Fried M, Duffy PE. Malaria during pregnancy. Cold Spring Harbor Perspectives in Medicine. Available at: https://doi.org/10.1101/cshperspect.a025551.

6. Al Hammadi A, Mitchell M, Abraham GM, Wang JP. Recrudescence of plasmodium falciparum in a primigravida after nearly 3 years of latency. Am J Trop Med Hygiene, 2017. Available at: https://doi.org/10.4269/ajtmh.16-0803.

7. Shulman CE, Dorman EK. Importance and prevention of malaria in pregnancy. Trans Royal Society Trop Med Hygiene, 2003. Available at: https://doi.org/10.1016/S0035-9203(03)90012-5.

8. Parise ME, Lewis LS, Ayisi JG, Nahlen BL, Stutsker L, Muga R, et al. A rapid assessment approach for public health decision-making related to the prevention of malaria during pregnancy. Bulletin World Health Organization. 2003;81:316-23.

9. Murphy SC, Breman JG. Medicine Lowa State University. Gaps in the childhood malaria burden in Africa: cerebral malaria. Neurological sequelae, anemia, respiratory distress, hypoglycemia, and complications of pregnancy. Am J Trop Med Hygiene. 2001;64(1-2 Supply):57-67.

10. Singh N. Epidemiology of falciparum and vivax malaria in pregnancy in India. Paper presented at a Symposium on Malaria in Pregnancy in Kisumu, Kenya, organized by the Centers for Disease Control and Prevention (CDC), Atlanta, and the Kenyan Medical Research Institute (KEMRI), Kenya; 1997.

11. Beeson JG, Rogerson SJ, Elliott SR, Duffy MF. Targets of protective antibodies to malaria during pregnancy. J Infect Dis. 2005;192:1647.

12. Desai M, Ter Kuile FO, Nosten F, McGready R, Asamoa K, Brabin B, et al. Epidemiology and burden of malaria in pregnancy. Lancet Infect Dis. 2007;7:93-104.

13. Endeshaw T, Gebre T, Ngondi J, Graves PM, Shargie $\mathrm{EB}$, Ejigsemahu $\mathrm{Y}$, et al. Evaluation of light 
microscopy and rapid diagnostic test for the detection of malaria under operational field conditions: A household survey in Ethiopia. Malar J. 2008;7:118.

14. A rapid dipstick antigen capture assay for the diagnosis of falciparum malaria. WHO informal consultation on recent advances in diagnostic techniques and vaccines for malaria. Bull World Health Organ. 1996;74:47-54.

15. Chotivanich K, Silamut K, Day NP. Laboratory diagnosis of malaria infection: a short review of methods. Aust J Med Sci. 2006;27:11-5.

16. Shulman CE, Dorman EK, Bulmer JN. Malaria as a cause of severe anemia in pregnancy. Lancet. 2002;360:494.
17. Abdalla S, Pasvol G. In: The Hematology of Malaria. Newton PN, Essien E, White NJ, editor. London: Imperial College Press. Platelets and blood coagulation in human malaria; 2004:249-276.

Cite this article as: Palem G, Pal SJ. Maternal and fetal outcome of malaria in pregnancy. Int J Reprod Contracept Obstet Gynecol 2019;8:4040-4. 